\title{
Impact of a water temperature shift on xenoma clearance and recovery time during a Loma salmonae (Microsporidia) infection in rainbow trout Oncorhynchus mykiss
}

\author{
Joy A. Becker*, David J. Speare \\ Department of Pathology and Microbiology, Atlantic Veterinary College, Charlottetown, \\ Prince Edward Island C1A 4P3, Canada
}

\begin{abstract}
Previous studies have modelled the relationship between water temperature and the rate of sporulation as defined by xenoma formation during microsporidial gill disease (MGD) in salmon caused by Loma salmonae. Although offering insight into the epidemiology of MGD, a key unexplored area is the role of temperature in the rate of xenoma dissolution including spore release into the environment, and this is crucial to our ability to model horizontal transmission of MGD within confined net-pen populations of farmed salmon. Results from a previous trial suggested that xenoma dissolution may be dramatically hastened as water temperature declines, thus introducing a critical anomaly into any predictive exercise. The data generated herein was evaluated using the statistics of survival analysis to re-establish the baseline relationship of xenoma formation and dissolution relative to water temperature and to compare these results with those of previous studies. We infected 30 individuals of Oncorhynchus mykiss (Walbaum) with macerated xenoma-laden gill material, and afterwards allocated them to tanks with water temperatures of 11,15 , or $19^{\circ} \mathrm{C}$ and monitored them through a disease cycle. Xenoma onset and clearance times were similar to previous findings with both events being accelerated at higher water temperatures, thereby suggesting a similar temperature response in the current strain to those used in previous studies. Another group of 45 fish was infected with $L$. salmonae and held at $15^{\circ} \mathrm{C}$ until xenomas formed, and were subsequently shifted to 11,15 , or $19^{\circ} \mathrm{C}$. The median xenoma dissolution time in these tanks was 49,35 and 28 d, respectively, similar to rates observed when water temperature remained constant. Thus we rejected the hypothesis that a sudden change in water temperature triggers rapid or anomalous xenoma dissolution.
\end{abstract}

KEY WORDS: Loma salmonae $\cdot$ Xenoma clearance $\cdot$ Temperature shift $\cdot$ Recovery time

\section{INTRODUCTION}

Within intensive fish-rearing systems, there has been an observed exacerbation of infections by parasites that are not considered severe pathogens in salmonids from other habitats (Kent 2000). One example of this observation is microsporidial gill disease (MGD) caused by Loma salmonae in net-pen-reared chinook and coho salmon (Oncorhynchus tshawytscha and $O$. kisutch) in coastal British Columbia, Canada.
Although common, L. salmonae is not usually considered a severe pathogen in wild salmon, however it is an important cause of disease in pen-reared chinook and coho salmon (Kent 2000, Georgiadis et al. 2001).

To provide a basis for the epidemiology of MGD, the rate of sporulation (xenoma formation) and spore release (xenoma dissolution) has been the subject of intensive investigation, and it has been reported that, in large part, the rate of these processes is determined by water temperature (Beaman et al. 1999, Becker et 
al. 2003), although the effect of species is not negligible (Ramsay et al. 2002). The pathogenesis of MGD has recently been elucidated, and the key events include oral uptake of an infectious spore, intragastric spore germination, a brief residence period in the gut lamina propria, and a 2 wk merogony-like phase in the cardiac subendothelium, followed by a macrophagemediated transport of the parasite to the gill where final development (further merogony and sporogony) occurs within gill pillar cells, with sporogony leading to the formation of a distended spore-filled xenoma (Sánchez et al. 2000, 2001, Rodríguez-Tovar et al. 2002). Development to the xenoma stage has been effectively modelled relative to the effects of temperature on the rate of xenoma formation. The permissible temperature range for this parasite to proceed to sporogony and xenoma formation is between 9 and $20^{\circ} \mathrm{C}$, with optimum parasite development at $15^{\circ} \mathrm{C}$ (Beaman et al. 1999). Using the direct exposure model with gastric intubation, Beaman et al. (1999) reported the mean xenoma onset time as 70,37 and 30 d postexposure (p.e.) for rainbow trout reared at 11, 15, and $19^{\circ} \mathrm{C}$, respectively.

Similar modelling of the rate of xenoma clearance has been more elusive, and yet it is the key event regarding transmission of infection and recovery of infected fish, and involves the induction of protective immunity. However, a recent report stated that the median clearance time for branchial xenomas was 10 and 12 wk p.e. using the direct per os exposure model and indirect cohabitation model, respectively (Ramsay et al. 2003). The xenoma clearance time was reportedly more intermittent than xenoma onset, and could possibly be dependent upon the initial dose of spores received (Ramsay et al. 2003). This was the first report to identify the importance of accurately quantifying the recovery period of MGD caused by Loma salmonae by measuring xenoma clearance and the duration of infectivity.

A critical unknown, hampering the direct application of laboratory studies (with constant water temperature) to the aquaculture setting (with fluctuating water temperatures as dictated by the ocean location) is the effect of water temperature fluctuation on disease transmission. For example, with constant water temperature, the rate of xenoma formation is highly predictable (Beaman et al. 1999). However, Speare et al. (1999) reported that when water temperature changed during a trial, the rate of xenoma formation was best predicted by the water temperature during early merogony and was not predicted by an accumulation of thermal units throughout the trial duration. Additionally, similar vagaries may frustrate our ability to predict the clearance of xenomas in conditions of water temperature change. Specifically, results from a previ- ous trial have led to the hypothesis that a sudden drop in water temperature may cause pre-formed xenomas to undergo a rapid rate of dissolution (Becker et al. 2003). A biological explanation could be that the temperature decline signals to the parasite the need to transmit to another naïve fish. In support of this, Speare et al. (1999) reported that the early stages of the parasite can remain dormant within an infected fish when at $5^{\circ} \mathrm{C}$ (which is below the permissive water temperature), and these parasites were able to recommence their typical life cycle once temperatures rose above permissible levels to $15^{\circ} \mathrm{C}$. However, an equally plausible explanation for the previously observed anomaly is that the life-cycle thermal dependence of the laboratory strain of Loma salmonae used in the trial may have differed from strains used in the previous trials.

The objectives of the current study were 2 -fold and interconnected. The main objective was to critically examine the hypothesis that a change in water temperature (particularly a decline in water temperature) may cause an accelerated dissolution of pre-formed xenomas. A secondary objective was to achieve a repeat observation of the rate of xenoma formation and dissolution at 3 constant permissible temperatures to determine whether the laboratory strain of Loma salmonae presently in use acts similarly to strains that generated previous historical data.

\section{MATERIALS AND METHODS}

Fish husbandry and maintenance. Juvenile rainbow trout (15 to $25 \mathrm{~g}$ ) were obtained from a certified disease-free (notifiable pathogens) commercial hatchery on Prince Edward Island with no history of Loma salmonae. The fish were housed in a flow-through system of $70 \mathrm{l}$ (habitable volume) circular fibreglass tanks ( $\mathrm{n}=4$ ) with a well-water source. The tanks received constant aeration and the oxygen levels were monitored using a Campbell scientific data logger (Model CR-7, Campbell Scientific Data Logging). The flow rate was maintained at $2.0 \mathrm{l} \mathrm{min}^{-1}$ because water turnover rate affects the transmission of $L$. salmonae (Becker et al. 2003). The rainbow trout were acclimatised to these conditions for $5 \mathrm{~d}$ prior to initiating the experiments. In all cases, the fish were anaesthetised and euthanised using benzocaine at a concentration of 60 and $100 \mathrm{mg} \mathrm{l}^{-1}$, respectively. All procedures were conducted in accordance with the guidelines of the Canadian Council on Animal Care.

Temperature control and monitoring. The water temperatures were $11,15(2$ tanks $)$, and $19^{\circ} \mathrm{C}\left( \pm 0.3^{\circ} \mathrm{C}\right)$. A 2-header tank system was used to ensure precision and consistency in water temperatures. One tank con- 
tained ambient well-water at approximately $11^{\circ} \mathrm{C}$, the other contained heated well-water at $27^{\circ} \mathrm{C}$. Heated water passed through an aeration/degassing column to prevent gas supersaturation. The 2 tanks of water mixed just before entering the experimental tanks to provide the desired temperatures. Water temperatures were monitored daily using a Fluke ${ }^{\circledR}$ armoured thermocouple (Fluke) and were recorded every $10 \mathrm{~min}$ using a Campbell scientific data logger Model CR-7.

Experimental design and method of infection. For the disease-exposure treatment, a pool of 80 naïve rainbow trout maintained at $15^{\circ} \mathrm{C}$ were fed infectious macerated gill material obtained from laboratorymaintained Loma salmonae infections; the time of feeding was subsequently considered as Day 0 p.e. (Kent et al. 1995, Shaw et al. 1998, Speare et al. 1998, Ramsay et al. 2001). On the following day, 30 rainbow trout were randomly allocated to the other experimental tanks (10 fish per tank) held at 11,15 , and $19^{\circ} \mathrm{C}$, respectively. This second cohort of fish (referred to as satellite fish) were exposed to $L$. salmonae spores at $15^{\circ} \mathrm{C}$ and subsequently transferred to 11,15 , or $19^{\circ} \mathrm{C}$ for the incubation and development of xenomas.

Beginning at Week 4 p.e. and continuing twice weekly, the satellite fish were examined under a stereoscope to determine if there were visible xenomas on the gill filaments. Xenoma intensity was measured by an index value based on the number of visible xenomas on the first left gill arch (Table 1). The intensityscore data generated from the satellite fish was recorded and tallied. The pool of 50 remaining rainbow trout were also scored twice weekly for the appearance of branchial xenomas. Once a fish was identified as having a score of 3 , a dorsal fin tag was sewn into the fish and it was randomly allocated to one of the temperature tanks held at 11,15 , or $19^{\circ} \mathrm{C}$. Xenoma monitoring continued until no further branchial xenomas were visible.

Data analyses. Survival analysis is a relatively new and useful tool used in the analysis of diseasetransmission models in fish research (Bebak-Williams et al. 2002, Becker et al. 2002, 2003, Ramsay et al. 2003). These statistical procedures are used for the

Table 1. Loma salmonae infecting Oncorhynchus mykiss. Xenoma intensity index for measurement of the number of visible branchial xenomas during a $L$. salmonae infection of rainbow trout

\begin{tabular}{|ll|}
\hline Score & \multicolumn{1}{c|}{ Description } \\
\hline 0 & No visible xenomas \\
1 & 1 visible xenoma per 6 gill filaments \\
2 & 1 visible xenoma per gill filament \\
3 & More than 1 visible xenoma per filament \\
\hline
\end{tabular}

analysis of data in which the outcome variable of interest is time until an event occurs, with the event defined as any designated experience (e.g. death, sero-conversion or xenoma clearance). Survival analysis was used to analyze the data collected from the first cohort of rainbow trout to evaluate the effect of a temperature shift on branchial xenoma clearance during a Loma salmonae infection. For this study, the survival time was calculated as the number of days after the shift in temperature until no branchial xenomas were visible. Using this data, survival probabilities were calculated and plotted for each temperature group in the form of a survivor function $S(t)$, defined as the probability that an individual will survive longer than some specified time, $t$ (Kleinbaum 1996). Survival functions are nonincreasing, and start at 1 and drop to zero. Specifically, the Kaplan-Meier (K-M) estimator (as described in Cleves et al. 2002) was used to calculate the survivor function for each group of fish held at 11,15 , or $19^{\circ} \mathrm{C}$. A Wilcoxon test was used to compare the survivor curves to determine statistical differences.

A proportional hazards $(\mathrm{PH})$ model was fit to the survival data generated from the first cohort of rainbow trout. This model calculates the hazard function for each temperature group, which is the probability of a fish failing at a specific time given that it did not fail before. In other words, the hazard function represents the instantaneous failure rate over time (Becker et al. 2003). For this study, on any given day the hazard function represents the probability of a fish no longer showing visible xenomas. The $\mathrm{PH}$ model compares the hazard of one temperature group to the hazard of another in the form of a ratio (Kleinbaum 1996). The $\mathrm{PH}$ model assumes that the hazard ratio is constant over time and is evaluated by looking for parallel lines on a plot of the log of the cumulative hazard against log time (Kleinbaum 1996, Cleves et al. 2002). Cox-Snell residuals were calculated to identify outliers. The whole survival analysis was completed using the software package STATA ${ }^{\mathrm{TM}}\left(\mathrm{Stata}^{\mathrm{TM}}\right)$ using -st(Series of commands used with survival time data) procedures as outlined by Cleves et al. (2002).

For the second cohort of rainbow trout, the mean xenoma-intensity score was calculated for each temperature group separately on all sample days using STATA. The means were graphed using lowess smoothed graphs with a band width equal to 0.15 .

\section{RESULTS}

The Kaplan-Meier survival curves measuring the time to branchial xenoma dissolution after the temperature shift for each group are plotted in Fig. 1. As water temperature decreased, the amount of time required to 


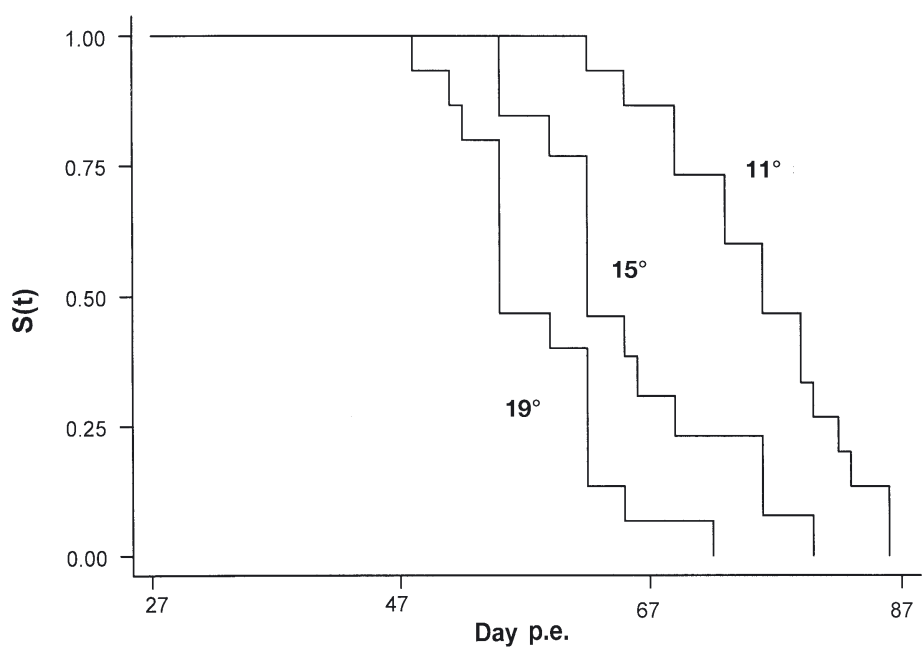

Fig. 1. Oncorhynchus mykiss. Kaplan-Meier survivor curves measuring the branchial xenoma clearance time for rainbow trout held at 3 temperatures post-exposure (p.e.) to a high oral dose of Loma salmonae spores

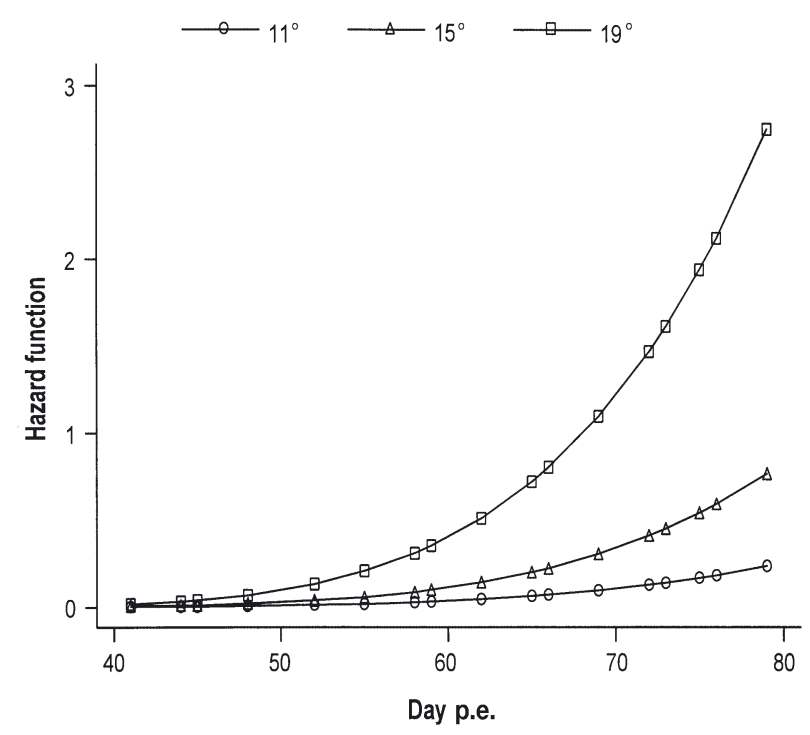

Fig. 2. Oncorhynchus mykiss. Hazard function measuring branchial xenoma clearance in each temperature group of rainbow trout, post exposure (p.e.) to a high oral dose of Loma salmonae spores

clear all branchial xenomas increased. Fish transferred to the $19^{\circ} \mathrm{C}$ tank after developing a severe level of branchial xenomas had a significantly reduced xenoma survival $(\mathrm{p}<0.0001)$. In other words, fish shifted to $19^{\circ} \mathrm{C}$ cleared their xenomas faster than fish shifted to 15 or $11^{\circ} \mathrm{C}$. The median xenoma clearance time was 49,35 , and $28 \mathrm{~d}$ after transfer to treatment tanks held at 11, 15, or $19^{\circ} \mathrm{C}$, respectively. The rainbow trout held at $11^{\circ} \mathrm{C}$ experienced a lagged or retarded branchial xenoma recovery period and did not show a rapid rate of dissolution with a sudden drop in temperature.
A parametric $\mathrm{PH}$ model using a Weibull distribution was fit to the xenoma' clearance data set to determine the relationship amongst the hazard functions for each temperature. The estimated hazard functions defined as the probability of a fish clearing all visible branchial xenomas for each temperature are plotted in Fig. 2. At any given time, a fish which was shifted to $15^{\circ} \mathrm{C}$ had a hazard that was 3.2 times greater than the hazard experienced by a fish transferred to the $11^{\circ} \mathrm{C}$ tank. Similarly, at any given time, a fish shifted to $19^{\circ} \mathrm{C}$ had a hazard that was 11.5 times greater than the hazard experienced by a fish transferred to $11^{\circ} \mathrm{C}$. In other words, on any given day, fish shifted to either 15 or $19^{\circ} \mathrm{C}$ were 3.2 and 11.5 times more likely to clear all branchial xenomas than fish shifted to $11^{\circ} \mathrm{C}$, respectively. The PH model assumption that the hazard ratio is constant over time was investigated, and there was no evidence of a violation $(\mathrm{p}=0.60)$. Examination of the Cox-Snell residuals did not reveal any outliers or influential observations.

The mean xenoma-intensity scores calculated from the satellite rainbow trout are plotted in Fig. 3. Each temperature group experienced a double peak in the mean xenoma scores followed by rapid decline and absence of xenomas. Satellite fish shifted to 19 and $15^{\circ} \mathrm{C} 1 \mathrm{~d}$ after Loma salmonae exposure had xenoma scores that quickly peaked on Days 32 and 42 p.e. and Days 35 and 42 p.e., respectively, whereas the fish shifted to $11^{\circ} \mathrm{C}$ were much slower to peak, on approximately Days 49 and 60 p.e. The fish held at $11^{\circ} \mathrm{C}$ displayed delayed xenoma formation, with only low levels of xenomas.

\section{DISCUSSION}

The defining role of temperature in the life cycle of Loma salmonae now includes the disease-recovery period during which branchial xenomas rupture and are no longer visible. This study is the first to accurately measure the impact of a temperature shift on the xenoma dissolution using the per os exposure model. As the water temperature of the transfer tank increased, the amount of time required for the dissolution of all branchial xenomas decreased. Therefore, the temperature during the exposure period or during the early developmental stages of merogony did not fix the development rate of this parasite. Additionally the acute temperature change did not alter the xenoma dissolution rate at the 3 temperatures investigated. Those rainbow trout shifted to $11^{\circ} \mathrm{C}$ during the disease-recovery period experienced a temperature-associated lag period in the rate of xenoma dissolution. Unfortunately, this result does not support the theory proposed regarding differ- 


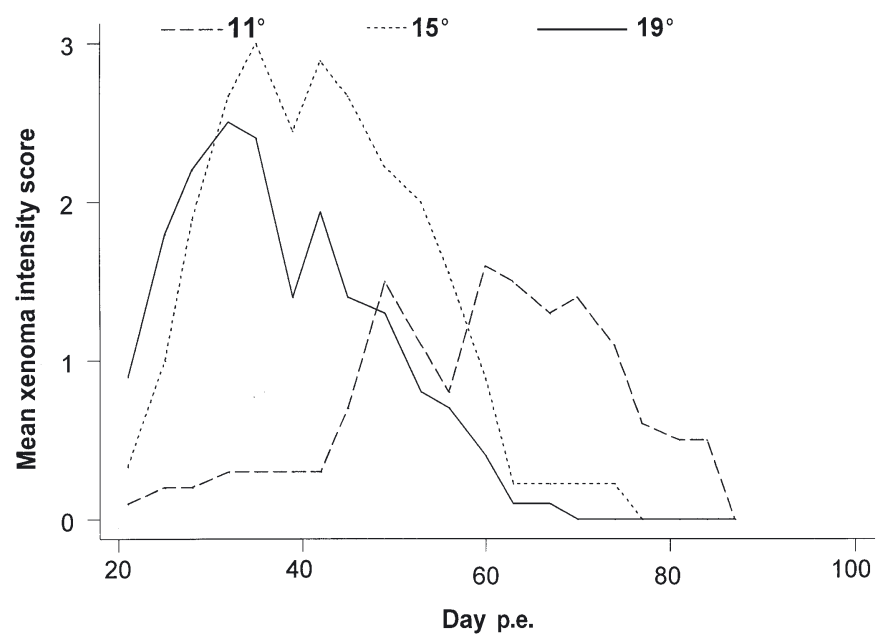

Fig. 3. Oncorhynchus mykiss. Mean xenoma intensity in rainbow trout held at 11,15 , or $19^{\circ} \mathrm{C}$ during Loma salmonae infection, using high-dose infection-exposure model on Day 0 post-exposure (p.e.)

ential xenoma rupture with sudden temperature change (Becker et al. 2003). Additionally, there was no evidence to suggest that the associated temperature-dependency of the life cycle of L. salmonae is a result of strain differences. However, the observed double peak at all 3 temperatures may account for the absent lag period reported by Becker et al. (2003) in rainbow trout held at $11^{\circ} \mathrm{C}$ using the cohabitationexposure model. The double peak in the mean xenoma scores suggests the possibility of early- and late-developing xenomas within one individual host. This information would be critical for efficiently managing a current outbreak of MGD caused by $L$. salmonae and for prevention of future disease episodes.

Water temperature is often recognised by fish farmers and scientists to be the dominant environment factor associated with several severe infectious diseases including those caused by Loma salmonae, Nucleospora (Enterocytozoon) salmonis and Gyrodactylus spp. There are a large number of gyrodactylids that parasitise cold-water fishes including salmonids (Anderson \& Buchmann 1998). G. derjavini is widely distributed on Danish rainbow trout farms, and is clearly influenced by temperature. Anderson \& Buchmann (1998) reported that $100 \%$ infection was possible at $5.5,11.6$, and $18.7^{\circ} \mathrm{C}$; however, at the coldest temperature, G. derjavini was significantly slower to reach maximum prevalence. A rapid decrease in the parasite numbers was evident after peak abundance occurred (Anderson \& Buchmann 1998). Quick recovery from the parasite invasion was also seen in the present study, with a dramatic reduction in branchial xenomas in the satellite fish after the peak was reached at all 3 temperatures investigated. Anderson \& Buchmann (1998) suggested that a host-response was involved in the elimination of $G$. derjavini following peak abundance. The immune responses by fishes are often weak or non-existent when microsporidians evade detection by being intracellular or by forming a xenoma, as is the case with L. salmonae (Shaw \& Kent 1999). Xenoma-forming microsporidians become susceptible to the fish immune system only after xenoma rupture, unless immunity has already been invoked. However, temperature does affect the ability to mount an immune response, as the phagocytic activity of macrophages is dependent on temperature (Shaw \& Kent 1999).

The non-xenoma-forming microsporidian Nucleospora salmonis is associated with severe anaemic conditions in chinook salmon, with a packed bloodcell volume as low as $5 \%$ (Shaw \& Kent 1999). The optimum temperature for the progression of infections occurs between 15 and $18^{\circ} \mathrm{C}$, with the permissible range between 9 and $21^{\circ} \mathrm{C}$ (Antonio \& Hedrick 1995). It was reported that at the low temperature of $9^{\circ} \mathrm{C}$, mortality due to $N$. salmonis was delayed and the resultant infections were considered mild (Antonio \& Hedrick 1995). A similar pattern was found with Loma salmonae in that the satellite fish at $11^{\circ} \mathrm{C}$ displayed a delayed rate of xenoma development of several weeks compared to fish held at 15 and $19^{\circ} \mathrm{C}$. Although $100 \%$ of the satellite fish at $11^{\circ} \mathrm{C}$ developed MGD, they showed considerably lower mean numbers of xenomas and were classified as having mild to moderate levels of disease. Interestingly, fish infected with $N$. salmonis at $9^{\circ} \mathrm{C}$ and subsequently shifted to $15^{\circ} \mathrm{C}$ at Week 12 p.e. developed severe infections, with significantly higher levels of mortalities than fish that remained at $9^{\circ} \mathrm{C}$ throughout the course of the disease (Antonio \& Hedrick 1995). Therefore, even at a relatively nonpermissive temperature of $9^{\circ} \mathrm{C}, N$. salmonis infection occurs and can rapidly progress to severe disease with an upward shift in temperature to $15^{\circ} \mathrm{C}$ (Antonio \& Hedrick 1995). In the present study, L. salmonae-exposed fish initially held at $15^{\circ} \mathrm{C}$ and subsequently shifted down to $11^{\circ} \mathrm{C}$ or up to $19^{\circ} \mathrm{C}$ showed an extended or reduced disease recovery period, respectively. As with N. salmonis, temperature was able to influence the final progression of MGD irrespective of the investigated water temperatures during the early stages of the parasite life cycle. This observation emphasises the importance of perpetual disease-surveillance, as the transmission potential of MGD is quite substantial at near nonpermissible water temperatures with mild levels of disease. 
Understanding how a pathogen such as Loma salmonae moves from fish to fish is crucial to effectively controlling its dissemination (Ramsay et al. 2001). During the course of outbreaks of MGD caused by L. salmonae, there are very few options available to fish farmers or health professionals to combat disease. Ramsay et al. (2001) reported that the transmission potential of L. salmonae appears to extend beyond the signs of disease. This observation, in combination with the influence of temperature on the clearance of xenomas from the gill filaments, may have serious consequences on the possible control and reduction of this disease. Typical control methods for many infectious salmon pathogens include fallowing to break the disease cycle, and separation of year classes to prevent possible spread of disease. These methods have also been suggested as possible measures for MGD control (Ramsay et al. 2001). However with the new knowledge regarding the effect of temperature on the recovery period, water temperature must be considered in the attempt to control this pathogen. Fallowing periods should be extended or reduced to reflect the water temperature at the outbreak site. The transmission potential of fish infected with $L$. salmonae in cold water is much greater than that of fish in warm water because the length of time in which the former are able to release infective spores is significantly longer. Outbreaks of $L$. salmonae with high mortality levels in chinook salmon tend to occur in late summer when water temperatures peak. Many fish-health specialists have focused on high water temperatures as a key-risk factor for disease (Beaman et al. 1999, Speare et al. 1999, Becker et al. 2003). However, the present study indicates that the transmission potential in cold water is also a key factor to disease control. For example, chinook salmon that survive the MGD outbreak in late summer possibly have the ability to release infective spores for many weeks or months as the water temperature begins to drop with the approaching winter. Additionally, chinook salmon have a much longer natural course of disease than rainbow trout, with the majority of fish clearing branchial xenomas by Week 20 p.e. (Kent et al. 1999). This observation, in combination with the extended transmission period of the parasite in cold water, greatly extends the infectious stage of MGD caused by L. salmonae in chinook salmon. Theoretically, it may be possible that a recovered chinook salmon is able to harbour a minimal number of infectious spores over the winter to be released when water temperatures are permissive in the spring and a naïve population in the form of newly transferred smolts is available for infection. Therefore, recovered salmon from the previous year class would provide an excellent perpetual reservoir of disease for any naïve salmon.
Acknowledgements. The authors wish to thank the staff of the Aquatic Facility at the Atlantic Veterinary College for monitoring the tank systems. Thank you to Drs. F. Markham, G. Conboy, S. Jones, D. Rainnie, I. Dohoo, and B. Ikede for their input on the experimental design, and to J. Daley for superb technical support. This research was funded by Project Loma, a Strategic Grant from the National Sciences and Engineering Research Council of Canada (D.J.S).

\section{LITERATURE CITED}

Anderson PS, Buchmann K (1998) Temperature dependent population growth of Gyrodactylus derjavini on rainbow trout, Oncorhynchus mykiss. J Helminthol 72:9-14

Antonio DB, Hedrick RP (1995) Effect of water temperature on infections with the microsporidian Enterocytozoon salmonis in chinook salmon. Dis Aquat Org 22:233-136

Beaman HJ, Speare DJ, Brimacombe M (1999) Regulatory effects of water temperature on Loma salmonae (Micro spora) development in rainbow trout. J Aquat Anim Health 11:237-245

Bebak-Williams J, McAllister PE, Smith G, Boston R (2002) Effect of fish density and number of infectious fish on the survival of rainbow trout fry, Oncorhynchus mykiss (Walbaum), during epidemics of infectious pancreatic necrosis. J Fish Dis 25:715-726

Becker J, Speare D, Daley J (2002) The transmission of Loma salmonae in a rainbow trout (Oncorhynchus mykiss) population: a survival analysis model. In: Hendry CI, McGladdery SE (eds) Aquaculture Association of Canada Special Publication Number 5. Print Atlantic, Moncton, New Brunswick, p 43-45

Becker JA, Speare DJ, Dohoo IR (2003) Effect of water temperature and flow rate on the transmission of microsporidial gill disease caused by Loma salmonae in rainbow trout, Oncorhynchus mykiss. Fish Pathol 38:105-112

Cleves MA, Gould WW, Gutierrez RG (2002) An introduction to survival analysis using Stata. Stata Press, College Station, TX

Georgiadis MP, Gardner IA, Hedrick RP (2001) The role of epidemiology in the prevention, diagnosis and control of infectious diseases of fish. Prev Vet Med 48:287-302

Kent ML (2000) Marine netpen farming leads to infections with some unusual parasites. Int J Parasitol 30:321-326

Kent ML, Dawe SC, Speare DJ (1995) Transmission of Loma salmonae (Microsporea) to chinook salmon in sea water. Can Vet J 36:98-101

Kent ML, Dawe SC, Speare DJ (1999) Resistance to reinfection in chinook salmon Oncorhynchus tshawytscha to Loma salmonae (Microsporidia). Dis Aquat Org 37: 205-208

Kleinbaum DG (1996) Survival analysis: a self learning text. In: Dietz K, Gail M, Krickeberg K, Singer B (eds) Statistics in the health sciences. Springer-Verlag, New York, p 4-82

Ramsay JM, Speare DJ, Sánchez JG, Daley J (2001) The transmission potential of Loma salmonae (Microspora) in the rainbow trout, Oncorhynchus mykiss (Walbaum), is dependent upon the method and timing of exposure. J Fish Dis 24:453-460

Ramsay JM, Speare DJ, Dawe SC, Kent ML (2002) Xenoma formation during microsporidial gill disease of salmonids caused by Loma salmonae is affected by host species (Oncorhynchus tshawytscha, O. kisutch, O. mykiss) but not by salinity. Dis Aquat Org 48:125-131

Ramsay JM, Speare DJ, Becker JA, Daley J (2003) Loma salmonae-associated xenoma onset and clearance in 
rainbow trout, Oncorhynchus mykiss (Walbaum): comparison of per os and cohabitation exposure using survival analysis. Aquac Res 34:1329-1335

Rodríguez-Tovar LE, Wright GM, Wadowska DW, Speare DJ, Markham RJF (2002) Ultrastructural study of the early development and localization of Loma salmonae in the gills of experimentally infected rainbow trout. J Parasitol 88:244-253

Sánchez JG, Speare DJ, Markham RJF (2000) Normal and aberrant tissue distribution of Loma salmonae (Microspora) within rainbow trout, Oncorhynchus mykiss (Walbaum), following experimental infection at water temperatures within and outside of the xenoma-expression temperature boundaries. J Fish Dis 23:235-242

Sánchez JG, Speare DJ, Markham RJF (2001) Altered tissue

Editorial responsibility: Wolfgang Körting,

Hannover, Germany distribution of Loma salmonae: effects of natural and acquired resistance. J Fish Dis 24:33-40

Shaw RW, Kent ML (1999) Fish Microsporidia. In: Wittner M, Weiss LM (eds) The microsporidia and microsporidiosis. ASM Press, Washington, DC, p 418-446

Shaw RW, Kent ML, Adamson ML (1998) Modes of transmission of Loma salmonae (Microsporidia). Dis Aquat Org 33: 151-156

Speare DJ, Arsenault GJ, Buote MA (1998) Evaluation of rainbow trout as a model for use in studies on pathogenesis of the branchial microsporidian Loma salmonae. Contemp Top Lab Anim Sci 37:55-58

Speare DJ, Beaman HJ, Daley J (1999) Effect of water temperature manipulation on a thermal unit predictive model for Loma salmonae. J Fish Dis 22:277-283

Submitted: July 8, 2003; Accepted: November 24, 2003 Proofs received from author(s): February 2, 2004 